\title{
Piaget's theory of cognitive development: a review
}

\author{
Pia Sanghvi \\ Independent Mental Health Professional / Psychotherapist, Mumbai \\ Corresponding Author: Pia Sanghvi \\ E-mail: piasanghvi.therapy@gmail.com (www.linkedin.com/in/piasanghvi).
}

\begin{abstract}
This article aims to provide a concise understanding of cognitive development in children through Jean Piaget's work. His journey of how he came upon subject, and constructed the theory has been included. Certain concepts as well as the four stages that encompass and define the theory have been highlighted. Lastly, a brief evaluation involving contributions to psychology, common criticisms and implications for the area of education has been covered.
\end{abstract}

Keywords: cognitive, development, Jean Piaget, children, theory, psychology

(Paper received $-29^{\text {th }}$ October 2019, Peer review completed $-10^{\text {th }}$ January 2020)

(Accepted $-12^{\text {th }}$ January 2020)

\section{INTRODUCTION}

"It is with children that we have the best chance of studying the development of logical knowledge, mathematical knowledge, physical knowledge, and so forth."

Jean Piaget

\section{Historical Background}

Jean Piaget (1896-1980) was born in Neuchâtel, Switzerland. He was the first-born son of Arthur Piaget and Rebecca Jackson. His father was a professor of medieval literature at the University of Neuchâtel [1]. As a child, Piaget developed an interest in animals and nature. When he was around the age of 10, he wrote a short scientific paper on the albino sparrow. By the time he reached adolescence his research on mollusks was widely known and published.

After high school, Piaget studied natural sciences at the University of Neuchâtel. He then went on to obtain two doctorates, one in natural sciences emphasizing biology and the other in philosophy with an emphasis in logic. He also published two philosophical essays. In 1918, Piaget spent a semester studying psychology at University of Zürich. It was there that he developed a keen interest for psychoanalysis.

In 1919, Piaget decided to go to Paris. During his time there he received an opportunity to work with Theodore Simon to help standardize intelligence tests [2]. He began working at the Ecole de la rue de la Grange-aux-Belles boys institution created by Alfred Binet, which was also used as a laboratory [3]. Piaget found the work of standardizing tests rather uninteresting. He, however, grew interested in the way children reasoned during the tests. It was then that he began studying the cognitive development of children.

Piaget used direct observation methods and began observing the development of his own children, which contributed to the construction of his theory. These factors met with criticism from psychologists in America. They claimed that his methods were along the lines of case studies and clinical observations rather than scientific experiments [2]. Withstanding the criticisms, Piaget's theory on cognitive development has remained a lasting contribution to developmental psychology. 
Piaget's theory is based on four stages or periods. He believed that children progress through the four stages in a fixed order, at differing rates. Children move from one stage to another when they reach the appropriate maturation level and have been exposed to certain relevant experiences. Piaget suggested that the stages do not end abruptly and that transition takes place slowly by merging into the next stage. $\mathrm{He}$ viewed cognitive development as a series of transformations with changes occurring over brief periods [4]. It is important to note that he emphasized on observing changes in 'quality' of children's understanding and knowledge rather than quantity.

\section{PIAGETIAN CONCEPTS}

\section{Schema}

A schema or scheme is defined as 'a concept or framework that organizes and interprets information' [5-6]. Piaget described schemas as basic building blocks to understand the world and organize knowledge. They are created and developed as and when children interact with their physical and social environments [7]. When children are young their schemas are related to sensorimotor or physical activity such as picking up a toy. However, as they start growing their schemas begin to reflect thought and move towards a more cognitive level. Piaget suggested that schemas could be developed through two processes - assimilation and accommodation. These processes are the means through which outside world knowledge can be internalized.

For example, a baby is given a new book. S/he may try to touch it, put it in their mouth, bang it on the floor or tear pages from it. Through experimentation at the sensorimotor stage, the child is trying to assimilate or accommodate the schema for a 'book'.

\section{Adaptation}

Adaptation is the child's tendency to develop and adjust schemas through experimentation and direct interaction with the environment. Adaptation consists of two processes, assimilation and accommodation. During childhood, children are constantly assimilating and accommodating new information in their schemas.

\section{Assimilation}

Assimilation is the process by which people fit new information into pre-existing concepts or schemas. Wadsworth [8] defines assimilation as 'the cognitive process by which a person integrates new perceptual matter or stimulus events into existing schemata or patterns of behavior' [9].

For example, a child sees a peacock for the first time. S/he notices that it has a beak and wings. The child points to animal and says, "bird". S/he has then assimilated the information into their existing schema for a 'bird'.

\section{Accommodation}

Accommodation is the process by which pre-existing concepts or schemas are restructured to include new information. If the new information cannot be altered, a new schema is formed. Wadsworth [8] defined accommodation as 'the creation of new schemata or the modification of old schemata' [9].

For example, a child believes that 'all furry four legged animals are dogs'. S/he then spots a cat and the child says, "Look a dog!". When s/he learns that it is in fact a cat and that furry four-legged animals are of various kinds, an accommodation has taken place. 


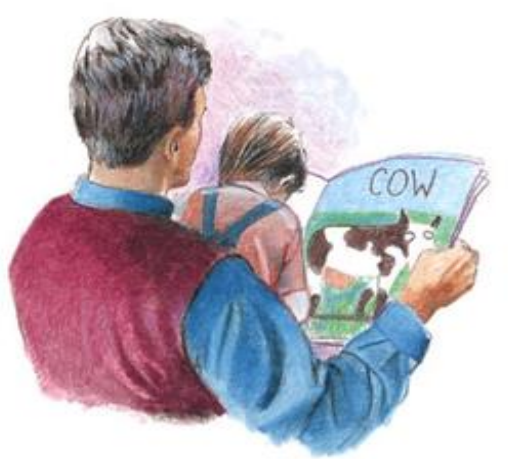

Two-year-old Gabriella has learned the schema for "cow" from her picture books.

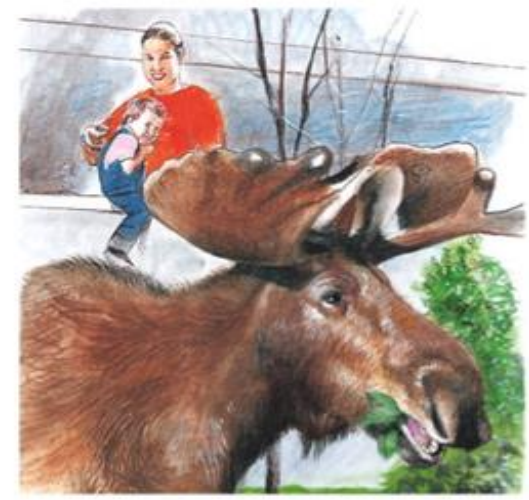

Gabriella sees a moose and calls it a "cow." She is trying to assimilate this new animal into an existing schema. Her mother tells her, "No, it's a moose."

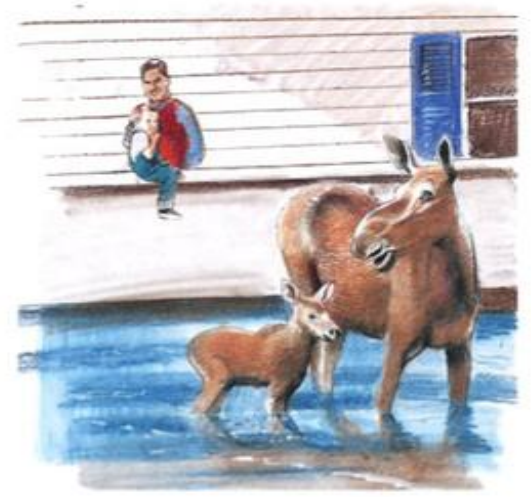

Gabriella accommodates her schema for large, shaggy animals and continues to modify that schema to include "mommy moose," "baby moose," and so forth.

\section{STAGES OF DEVELOPMENT}

Piaget divided cognitive development into four periods or stages: (1) sensorimotor stage, (2) preoperational stage, (3) concrete operational stage and (4) formal operational stage. Children progress through each stage in a sequential manner. Each stage is characterized by qualitatively different ways of thinking and cognitive growth. Below is an explanation of all four stages, the approximate ages and major characteristics of cognitive development that are generally observed. A note to clinicians, individual differences need to be accounted for while observing the development of children.

\section{Sensorimotor Stage (Birth to 2 years)}

The first stage in Piaget's theory is the sensorimotor stage, which lasts from birth to approximately 2 years of age $[4,10-12]$. During this stage infants observe their surroundings using the senses of sight, touch and sound. This stage of cognitive development is divided into six substages [13] -

\section{Substage 1: Simple Reflexes}

The first substage of the sensorimotor period encompasses of basic reflex actions. This stage begins at birth to the age of 1 month. The infant applies a set of action patterns such as, sucking, biting and grasping. These reflexes become the center of the infant's cognitive and physical life. It has been found that assimilation and accommodation begin to take as early as this.

For example, when the corner of the baby's mouth is stroked or touched, the baby will turn its head and open his/her mouth to follow the direction of the stroking. This reflex helps the baby find the breast or bottle while feeding.

\section{Substage 2: First habits and primary circular reactions}

This substage occurs from 1 to 4 months of the infants' life. During this period, infants begin to integrate simple reflex actions by coordinating separate action patterns. The main locus during this period is still the infant's own body. Primary circular reactions are schemas that are repeated because they are interesting or pleasurable for the infant. These repetitive, chance reactions help them build cognitive schemes that eventually become habits.

For example, Infants may repeat the action of sucking their thumbs or waving their arms and legs. 


\section{Substage 3: Secondary circular reactions}

In the third substage the baby's interest of the environment increases. This period occurs from 4 to 8 months of age. Piaget called these schemes 'secondary circular reactions' because the focus of attention tends to shift away from ones own self to the external world.

For example, the child may pick up a rattle and keep shaking it.

\section{Substage 4: Coordination of secondary circular reactions}

This substage lasts from 8 to 12 months. During this period the beginning of goal-directed behavior is observed. Infants coordinate and combine certain schemas to execute an action. The child starts to understand the difference between a means and an end (cause and effect). This leads to the development and achievement of object permanence. Object permanence refers to 'the realization that people and objects exist even when they cannot be seen' [13].

For example, the child will move an object out of the way to reach for another.

\section{Substage 5: Tertiary circular reactions}

Beginning at 12 months, this substage continues till the child is 18 months of age. In this substage the infant carries out mini experiments to learn about the environment. They become fascinated with the properties of an object and experiment with new behavior. Through these experiments, schemas are altered and adapted. Children begin to solve problems using the trial-and-error method.

For example, an infant may experiment by dropping his/her toy or food onto the floor from a high chair to see the effect that it had.

\section{Substage 6: Beginnings of thought}

This substage is characterized by the beginning of insight and creativity. This stage occurs from 18 months to 2 years. The major achievement of this stage is the capacity for mental representations. Major characteristics observed during this period are make-believe activity, complex schematic understanding, acceptance of others but with focus on self and internalization of images or past events.

For example, the child's play begins to involve imaginary creatures.

\section{Preoperational Stage}

In the preoperational stage the child's use of symbolic thinking grows. This period occurs when the child is 2 to 7 years old. During this stage the child begins to form mental representations of events and ideas. They are also able to communicate using words, gestures and symbols. For example: The child may see his/her mother holding a pair of shoes which may prompt the question, "We go out?'. In this manner children rely less on sensorimotor activity and more on mental representations to understand the world around them. Key aspects of this stage include -

> Conservation: The child's understanding that a certain quantity will remain the same despite change in arrangement or physical appearance. For example: A child is shown two glasses of water, one short and the other tall. The short, broad glass is filled with water. The same amount of water is then transferred from the short glass to the tall, thin glass. The child is asked whether there is more water in the second glass. If the child has mastered the concept of conversation $\mathrm{s} / \mathrm{he}$ will answer saying, 'No'.
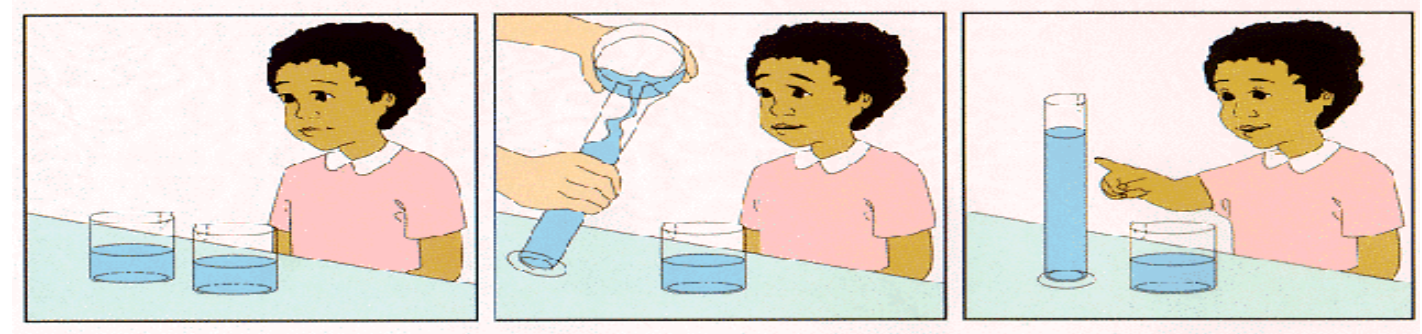
$>$ Centration: The tendency to focus on one aspect of a stimulus. Children make judgments based on the most outstanding feature or aspect in their perceptual array of sight. For example: A child is shown two arrangements of circles. One is clustered together in a symmetrical arrangement while the other is slightly spaced out. The child is then asked to point to the row that contains more circles. S/he will end up focusing on the superficial aspect of arrangement i.e. appearance rather than the quantity and point to the spaced-out arrangement.

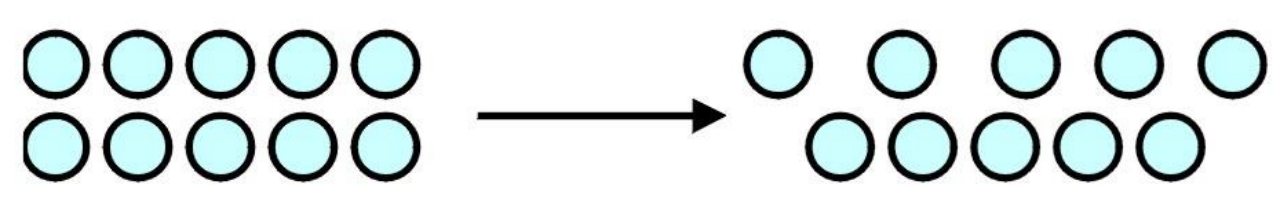

D Egocentricism: The child's inability to see the world from another's perspective. Egocentric thought refers to thinking that does not take into account the views of others. One way to understand this concept is Piaget's' three-mountains task. A child was presented with a threedimensional model containing three mountains. They looked at the model from one perspective (e.g. Location A) while a doll was placed in another location (e.g. Location B). The doll's perspective was different from that of the child's. The child was asked to choose the dolls point of view (literally). Most children stated that the doll's view was the same as what they could see. Let us discuss egocentric thought using an example. A child assumes that since $\mathrm{s} / \mathrm{he}$ has an elder brother therefore s/he is a younger sibling. In turn s/he believes that all his classmates have elder siblings. It should be noted that this process is not the same as selfishness, it is a part of the natural course of development and is not a lasting pattern of behavior.

\section{Concrete Operational Stage}

The concrete operational stage occurs between ages 7 and 11 or 12 . This stage is characterized by logical operations. The main change during this stage is that the child's thinking becomes less dependent on perception and more focused on logic. Children are better able to understand conservation tasks in this period. They are able to focus on multiple aspects of a stimulus, an ability known as 'decentering'. Once concrete operations begin taking hold, children grasp the concept of 'reversibility'. Reversibility is the notion that transformations of a stimulus can be reversed. For example, the children learn that a ball of clay that is turned into a long, thin rope can return to the shape of a ball again.

\section{Formal Operational Stage}

Children enter the formal operational stage at the age of 11 or 12 . During this stage the young adolescent learns how to think abstractly. A major element of this stage includes the ability to reason. Adolescents learn the concepts of deductive and inductive reasoning and apply their knowledge by solving problems and conducting experiments. The pendulum problem is often used to describe the reasoning ability at this stage. For example: An adolescent is shown a pendulum. S/he is then asked to determine factors that are responsible for the movement of the pendulum. The option to alter the length of the string, amount of force, weight, and height is given to the participant. The child will then form and test a series of hypotheses to come to a conclusion.

\section{CONTRIBUTIONS OF PIAGET'S THEORY}

- Piaget's work on cognitive development has remained a contribution to the areas of child and developmental psychology. His theory was one of the first to explain and describe the process of child development. 
- The theory is studied and applied by various researchers even today. Furthermore, applications to the fields of engineering, education, therapy and other such areas have been explored.

- Piaget was a great reporter of children's behaviors. He provided detailed descriptions of their cognitive abilities. He introduced useful concepts to cognitive psychology such as schemas, object permanence, egocentricism etc.

- Piaget's questions on cognitive development lead thousands of researchers to study the area. Hence, a large amount of research exists that helps us understand children and their cognitive growth.

\section{CRITICISMS}

- Piaget assumed that those children who were unable to perform various cognitive tasks lacked the underlying cognitive structure. This assumption is not valid as there are various factors that can affect a child's performance. Piagets tendency to equate task performance with competency has been criticized.

- Even though Piaget mentioned that cultural factors influence the growth of cognition, he devoted little attention to social and cultural influences. He also did not take into account how children develop through social interactions.

- Piaget provides a vague explanation of cognitive growth. He has been criticized for using abstract terms and pairing them with difficult tasks. Researchers now look upon his theory as an elaborate description of cognitive development that has limited explanatory power [14].

- Piaget maintained that cognitive development occurs in stages, which are holistic structures. Many have challenged this assumption of holistic structures. They also questioned whether cognitive growth does in fact take place in sequential stages.

\section{IMPLICATIONS FOR EDUCATION}

- Teachers can individualize learning experiences based on the child's stage of cognitive development.

- Children can be encouraged to experiment the various hypotheses and ideas that they form in order to come up with their own conclusions and opinions.

- Learning can be perceived as restructuring and constantly adapting cognition.

- Methods to enhance cognitive development through experiential learning can be explored.

\section{REFERENCES}

1. Smith L. A brief biography of Jean Piaget. Jean Piaget Society: Society for the Study of Knowledge and Dissemination, 2000.

2. Fleming J. Piaget and cognitive development. PhD Master Thesis. 2004.

3. Lascarides VC, Hinitz BF. History of early childhood education. Routledge; 2013.

4. Bjorklund DF. Behavioral Epigenetics: The Last Nail in the Coffin of Genetic Determinism. Human Dev 2018;61(1):54-9.

5. Piek JP. Infant motor development. Human Kinetics; 2006.

6. Marszalek JF, Myers JE. Dream interpretation: A developmental counseling and therapy approach. J Ment Health Couns 2006;28(1):18-30.

7. Cahan ED. The genetic psychologies of James Mark Baldwin and Jean Piaget. Dev Psychol 1984;20(1):12850 .

8. Wadsworth BJ. Piaget's theory of cognitive development: An introduction for students of psychology and education. McKay; 1971.

9. Ginsburg HP, Opper S. Piaget's theory of intellectual development. Prentice-Hall, Inc; 1988.

10. Gallagher JM, Reid DK. The learning theory of Piaget and Inhelder. iUniverse; 2002.

11. Müller U, Carpendale JI, Smith L, editors. The Cambridge companion to Piaget. Cambridge University Press; 2009.

12. Singer DG, Revenson TA. A Piaget primer: How a child thinks. International Universities Press, Inc. 1997.

13. Brainerd CJ. Piaget's theory of intelligence. Prentice Hall; 1978. 
14. Carey WB, Crocker AC, Elias ER, Feldman HM, Coleman WL. Developmental-Behavioral Pediatrics EBook. Elsevier Health Sciences; 2009.

15. Shaffer DD, Kipp K. Developmental psychology: Childhood \& adolescence: Childhood and adolescence. Cengage Learning; 2010.

$* * * * * * * * * * * * * * * * * * * * * * * * * * * * * * * * * * * *$

Acknowledgements - Nil

Conflict of Interest - Nil

Funding - Nil 